\title{
TRAJETÓRIA DOCENTE: VIVÊNCIAS DE UMA PROFESSORA DA INFÂNCIA NA FRONTEIRA
}

\author{
Luciene Cléa Silva ${ }^{1}$ \\ Leandro Baller ${ }^{2}$
}

\begin{abstract}
RESUMO: Objetivamos compreender as vivências de uma professora da infância, de Pedro Juan Caballero (PY), acerca da profissão docente, entre 1970 e 1980. A metodologia respaldou-se na história oral, usando a entrevista como instrumento de registros das narrativas de experiências de indivíduos, apresentando contribuições teóricas que se configuram como uma das ferramentas que auxiliam na compreensão do processo de desenvolvimento da sociedade. A fundamentação teórica alicerçou-se em Elias (1994), Meihy (1994,2006), Portelli (1997), Sarat (2004, 2015), Sarat e Santos (2010) Tanuri (2000), entre outros. Refletimos acerca das vivências da professora, ampliando nossos saberes sobre a história da formação e do trabalho docente de profissionais da educação naquele período, voltando-nos para a entrevistada que narra sobre o "constituir-se docente", "a escolha da profissão" e sobre as "vivências mais significativas com as crianças", na constituição da história da educação da fronteira. São reflexões iniciais de um Projeto de Pesquisa, que investiga a história da infância na fronteira do Brasil com o Paraguai; as trajetórias de formação de professores/as e as práticas pedagógicas que envolvem o cotidiano da infância na fronteira. A história da formação docente no Brasil e no Paraguai e a trajetória destes/as profissionais que mostram diferentes temáticas em diferentes contextos.
\end{abstract}

Palavras-chave: Vivências; Professora da Infância; Fronteira.

\section{TRAYECTORIA DE LA ENSEÑANZA: EXPERIENCIAS DE UNA MAESTRA DE INFANCIA EN LA FRONTERA}

RESUMEN: Nuestro objetivo es comprender las vivencias de una maestra de infancia, de Pedro Juan Caballero (PY), sobre la profesión docente, entre 1970 y 1980. La metodología se apoyó en la historia oral, utilizando la entrevista como instrumento para registrar las narrativas de las vivencias de individuos, presentando aportes teóricos que se configuran como una de las herramientas que ayudan a comprender el proceso de desarrollo de la sociedad. La teoria se basó en Elias (1994), Meihy (1994,2006), Portelli (1997), Sarat (2004, 2015), Sarat y Santos (2010), Tanuri (2000), entre otros. Reflexionamos sobre las vivencias de la docente, ampliando nuestro conocimiento sobre la historia del labor formativo y docente de los profesionales de la educación en ese

\footnotetext{
${ }^{1}$ Doutora em Educação pela Universidade Federal da Grande Dourados - UFGD, Mestre em Educação pela Universidade Católica Dom Bosco - UCDB, graduada em Letras e Pedagogia, docente do curso de Pedagogia do Campus de Ponta Porã, da Universidade Federal de Mato Grosso do Sul - UFMS. E-mail: luciene.silva@ufms.br

${ }^{2}$ Doutor em História, Docente da Universidade Federal da Grande Dourados - UFGD. E-mail: lballer@ufgd.edu.br
} 
período, acudiendo al entrevistado que narra sobre "convertirse en docente", "la elección de profesión” y sobre las "experiencias más significativas con la niñez", en la constitución de la historia de la educación fronteriza. Son reflexiones iniciales de un Proyecto de Investigación, que investiga la historia de la infancia en la frontera entre Brasil y Paraguay; las trayectorias de la formación docente y las prácticas pedagógicas que involucran la vida cotidiana de los niños de la frontera. La historia de la formación docente en Brasil y Paraguay y la trayectoria de estos profesionales que muestran diferentes temáticas en diferentes contextos.

Palabras-clave: Experiencias; Maestra de infancia; Frontera.

\section{INTRODUÇÃOO}

A história da formação docente, demarcada desde o final do século XIX e início do século $\mathrm{XX}$, tem sido investigada, por muitos autores e sob diferentes perspectivas, despertando assim formas distintas de se constituir uma reflexão teórica acerca deste processo, o que nos leva, por ora, tecer diálogos com alguns autores, consoante o intuito de compreender algumas destas reflexões. Este texto é parte de uma pesquisa maior, a qual almeja estudar as memórias de professoras da infância, no contexto da fronteira, no período de 1970 a 2000, por isso torna-se relevante conhecer como se constitui esta história da formação docente no Brasil, ao longo do período acima delimitado, buscando articulá-la com o contexto histórico da formação docente no Paraguai, visto que ao abordar a fronteira, noutro momento destacaremos as vivências de professoras de Ponta Porã (BR) e Pedro Juan Caballero (PY).

A fronteira internacional entre Ponta Porã (BR) e Pedro Juan Caballero (PY) apresenta muitas particularidades, dentre elas, o fato de não possuir nenhuma alfândega, barreira física ou fluvial que divide as duas cidades, ou seja, constitui-se como fronteira seca, separada apenas por uma rua - pertencente aos estados em contato - a qual é considerada uma "zona neutra" e não pode ser tocada. Tais aspectos fazem com que Ponta Porã seja considerada cidade-gêmea, ou cidade geminada de Pedro Juan Caballero. De acordo com a Portaria $\mathrm{n}^{\circ} 125$, de 21 de março de 2014, do Ministério da Integração Nacional:

Art. $1^{\circ}$ - Serão considerados cidades-gêmeas os municípios cortados pela linha de fronteira, seja essa seca ou fluvial, articulada ou não por obra de infraestrutura, que apresentem grande potencial de integração econômica e cultural, podendo ou não apresentar uma conurbação ou semi-conurbação 
com uma localidade do país vizinho, assim como manifestações "condensadas" dos problemas característicos da fronteira, que aí adquirem maior densidade, com efeitos diretos sobre o desenvolvimento regional e a cidadania.

Art. $2^{\circ}$ - Não serão consideradas cidades-gêmeas aquelas que apresentem, individualmente, população inferior a 2.000 (dois mil) habitantes.

A conurbação existente entre Ponta Porã (BR) e Pedro Juan Caballero (PY) agrega uma população de mais de 212.000 habitantes, visto que no censo de 2020 a população Pontaporanense foi estimada em 93.937 habitantes (IBGE, 2020). Segundo pesquisa realizada pela Dirección General de Estadísticas, Encuestas y Censos (DGEEC, 2015), na qual é verificada a "População nacional estimada e projetada, segundo sexo, departamento e distrito, 2000-2025", o distrito de Pedro Juan Caballero tem uma população projetada para o ano de 2018 (período mais recente encontrado) com um total de 118.939 pessoas.

Desta forma, compreendemos que a proximidade entre os países ultrapassa o limiar do espaço geográfico, e a fluidez da fronteira permite aos povos fronteiriços estabelecer relações e vivências que ampliam as potencialidades de intercâmbios entre pessoas, culturas, ações educativas e formativas, situações que envolvem o ser humano e a sociedade, atividades econômicas, constituições históricas e também as tensões comuns ao meio fronteiriço (SILVA, 2020).

Pensar nesta fronteira como lócus da fala de uma professora que se formou e exerceu a docência com crianças, aguça um olhar para uma fronteira dinâmica, fluida, porosa, como um lugar de muitos contatos e relações, repleta de uma ambiência em si, que "[...] traz sua própria historicidade, tornando-se o limiar do limite, opondo-se ao conceito de espaço naturalizado que a ela foi designado durante muito tempo no interior das ciências" (BALLER, 2014, p. 15).

O recorte para este momento centrou-se nas vivências de uma professora da infância, a qual reside e lecionou em Pedro Juan Caballero (PY), e narra acerca da constituição de sua profissão docente, destacando o período de 1970 a 1980 como o início de suas práticas profissionais com a infância. A escolha pelo termo professora, no feminino, acontece pelo fato de ser marcante o número de mulheres que trabalharam com a infância neste momento, tanto no Brasil, como no Paraguai, principalmente no período inicial o qual nos remete ao processo em que a mulher busca um lugar no 
mercado de trabalho e a feminização do magistério se caracteriza como o processo de formação inicial destas profissionais.

A intenção é apresentar como este histórico da trajetória docente desta professora de Pedro Juan Caballero (PY), diante das suas perspectivas sobre o "constituir-se docente", sobre "a escolha da profissão" e sobre as suas "vivências mais significativas com as crianças", pode dar corpo à compreensão da constituição da história da educação da região fronteiriça. O que nos leva a buscar uma reflexão articulada entre o contexto histórico de alguns aspectos organizacionais acerca da educação brasileira, bem como da educação paraguaia e ao processo de formação de professores/as.

Utilizamos a história oral para registrar as narrativas e vivências da professora escolhida para fazer parte deste texto, com o intuito de, a partir desta riquíssima ferramenta que estreita contatos, possibilita registros, fundamenta revelações e encaminha meios de compreensões, conhecer o processo de desenvolvimento da história de formação desta docente e do seu trabalho com as crianças, almejando assim a compreensão do processo de desenvolvimento da sociedade a partir de histórias de pessoas que nela vivem. Assim, a história oral apresenta-se como um meio que abre caminhos para a revelação de histórias que são relevantes tanto para quem conta como para quem ouve.

\section{BREVE HISTÓRICO DA FORMAÇÃO DOCENTE NESTE CONTEXTO}

O contexto histórico que abarca o processo de formação docente no Brasil, no final do século XIX e início do XX é permeado por inúmeras transformações no âmbito social, político, cultural, bem como no âmbito educacional. Ao direcionarmos nosso olhar, especificamente para o contexto de formação de professoras da infância, podemos destacar que desde o surgimento das primeiras instituições responsáveis pela formação no curso Normal, o referido processo, em muitos casos, segundo Tanuri (2000), objetivava formar profissionais que pudessem ensinar as crianças a ler e escrever na língua nacional, as quatro operações matemáticas, alguns aspectos de geografia e princípios de moral cristã. 
Assim, Tanuri (2000) apresenta que a primeira escola Normal brasileira foi criada na Província do Rio de Janeiro, de acordo com a Lei ${ }^{\circ} 10$, de 1835, definindo que:

\begin{abstract}
Haverá na capital da Província uma escola normal para nela se habilitarem as pessoas que se destinarem ao magistério da instrução primária e os professores atualmente existentes que não tiverem adquirido necessária instrução nas escolas de ensino mútuo ${ }^{3}$, na conformidade da Lei de 15/10/1827 (TANURI, 2000, p. 64).
\end{abstract}

Destaca-se que no Mato Grosso, a primeira escola Normal, para formação de professores data do ano de 1874 (SIQUEIRA, 1999, p. 210, apud TANURI 2000, p. 64). A organização didática do curso que era oferecido nestas escolas era bem simples e tinha a duração de dois anos. Neste mesmo período várias escolas foram criadas em muitos outros estados brasileiros, porém não obtiveram sucesso e logo foram perdendo seu espaço, e gerando assim uma descrença na formação de professores.

Segundo alguns registros, no período de criação das primeiras escolas Normais, a formação de profissionais era destinada apenas a homens, excluindo a mulher também deste meio. Porém, no final do Império, transformações ideológicas, políticas e culturais começaram a se intensificar no meio social e, consequentemente, a permear o espaço educacional.

\begin{abstract}
As primeiras escolas normais - de Niterói, Bahia, São Paulo, Pernambuco, entre outras - foram destinadas exclusivamente aos elementos do sexo masculino, simplesmente excluindo-se as mulheres ou prevendo-se a futura criação de escolas normais femininas. Aliás, mecanismos de exclusão refletiam-se mesmo na escola primária, onde o currículo para o sexo feminino era mais reduzido e diferenciado, contemplando o domínio de trabalhos domésticos. Nos anos finais do Império, as escolas normais foram sendo abertas às mulheres, nelas predominando progressivamente a frequência feminina e introduzindo-se em algumas a coeducação (TANURI, 2000, p.66).
\end{abstract}

Em meio a estas transformações novos ideários e caminhos começam a ser traçados no cerne da escola Normal, que além da abertura para a atuação da mulher em seu espaço, começa a rever e ampliar o seu currículo, visto que havia uma perspectiva

\footnotetext{
3 "Em $1^{\circ}$ de março de 1823, um Decreto "cria uma escola de primeiras letras pelo método de ensino mútuo para instrução das corporações militares" (TANURI, 2000, p. 63).
} 
de ensino, estabelecido por um acordo de "Cooperação do Poder Central no âmbito da instrução primária e secundária nas províncias" (TANURI, 2000, p.66), ampliando o ideário de popularização do ensino.

É nesse contexto que pensadores e políticos (TANURI, 2000) passam a atribuir como função da mulher a responsabilidade pela educação da infância, vista assim como um prolongamento de seu papel de mãe que cuida e educa. Assim, começa-se a vislumbrar uma saída para a mão de obra na escola primária, que em função da baixa remuneração, deixa de ser atrativa para os homens, e passa a ser proposta como uma possibilidade de conciliação das atividades domésticas da mulher com o exercício do magistério. E é neste contexto que a relação entre a educação da infância e a feminização do magistério vai se constituindo, desde o final do século XIX.

No século XX, principalmente em função das transformações sociais pelas quais passavam a sociedade, momento em que muitas mulheres começavam a exercer um cargo fora do seu ambiente doméstico, trabalhando especialmente nas fábricas e no comércio, o desenvolvimento da sociedade capitalista vislumbrava uma nova organização de sociedade e família, fazendo com que a mulher buscasse cada vez mais seu espaço no mercado de trabalho, necessitando também de quem acolhesse seus filhos. Sendo assim, surge a necessidade de criação e ampliação de espaços que pudessem receber estas crianças e, consequentemente, a precisão de profissionais que se dispusessem a ensiná-las também aumenta.

Esta forma de reorganização social, com o fato de a mulher passar a ocupar outros espaços, que não apenas os seus lares, ainda buscava manter as relações de poder que perpassavam por este meio, visto que estas mulheres e também as crianças faziam parte de um processo que também consistia em uma nova forma de organizar a sociedade.

Segundo Sarat (2015), no diálogo com Elias (1994), pode-se dizer que tal forma de organização se caracterizava pela configuração de redes de interdependências, num processo de "civilizar, instruir, formar e educar as populações. A proposta era inseri-las no contexto das ideias que circulavam no período e apontavam concepções de progresso e civilidade, como modelos de desenvolvimento para os países da América Latina [...]" (SARAT, 2015, p. 02). No diálogo com Elias (1994) torna-se relevante considerar que: 


\begin{abstract}
A rede de interdependência entre os seres humanos é o que os liga. Elas formam o nexo do que é aqui chamado configuração, ou seja, uma estrutura de pessoas mutuamente orientadas e dependentes. Uma vez que as pessoas são mais ou menos dependentes entre si, inicialmente por ação da natureza e mais tarde através da aprendizagem social, da educação, socialização e necessidades recíprocas socialmente geradas, elas existem, poderíamos nos arriscar a dizer, apenas como pluralidades, apenas como configurações. Eis o motivo porque [...] não é particularmente frutífero conceber os homens à imagem do homem individual. Muito mais apropriado será conjecturar a imagem de numerosas pessoas interdependentes formando configurações (isto é, grupos ou sociedades de tipos diferentes) entre si (ELIAS, 1994, p. 249).
\end{abstract}

Para Elias (1994) esta rede de interdependência entre as pessoas, volta-se para a configuração dos processos sociais norteados pela sociogênese (processo sóciohistórico) do grupo, por meio do qual as transformações sociais são percebidas e desencadeiam mudanças individuais, por meio da psicogênese do indivíduo, que influencia no comportamento deste em seu meio social. Desta forma, o processo civilizador pode ser caracterizado por esta transformação das estruturas individuais, principalmente porque estas estão em harmonia com a concepção de sociedade que as norteia, ou seja, a partir de uma 'sociedade dos indivíduos'.

Esta sociedade, composta por indivíduos interdependentes precisa ser compreendida também na perspectiva da história da formação docente ocorrida no Paraguai e mesmo que em período não síncrono ao do Brasil. Por isso é importante destacar que a mesma inicia no final século XVI, quando surgem as escolas de primeiras letras no país, o que segundo Cardozo (1996) gera o anseio em formar professores para tal demanda. Inicialmente as instituições formativas apresentaram uma organização de caráter particular, promovida pela igreja e seguindo os dogmas religiosos. Com a reestruturação da sociedade e a influência da colonização espanhola, o Cabildo passou a controlar algumas funções municipais, políticas e jurídicas e a assumir a responsabilidade pela educação (SILVA, 2020).

Hernandarias, considerado o primeiro intelectual paraguaio, estava à frente de várias movimentações pela educação no país, principalmente na tentativa de criação da Universidade desde 1603, o que só aconteceu em 1890 e não foi acompanhada por Hernandarias. Entretanto, a persistência deste intelectual em valorizar a formação docente ganhou destaque no momento em que reuniu os professores em Assunção, em 
1609, para o exame de maestros, e historicamente registrou a criação da primeira Escola Normal para professores do Paraguai:

[...] Hernandarias concentro en Asunción a todos los de la Provincia y los sometió a examen a cargo de los jesuítas. En uno de sus memoriales al rey, cuenta Hernandarias que le costó bastante trabajo reunir los maestros, pero no se quejó de los resultados de este examen. En realidade puede estabelecerse que esa reunión de maestros fue la primera Escuela Normal que tuvo el Paraguay. Se efectuó hacia 1609 (CARDOZO, 1996, p. 95).

Em 1811, com o declínio da colonização espanhola, o Paraguai passou por um período revolucionário, no qual recebeu influência francesa e norte-americana. No bojo das muitas transformações ocorridas em âmbito social, econômico, político, político, cultural e educacional, várias ações em busca da consolidação da educação foram acontecendo, dentre elas a proposta de Hernandarias, publicada em forma de documento, no dia 06 de janeiro de 1812, defendendo a instrução e boa educação do homem como meio de elevá-lo ao poder, heroísmo e como base de todas as demais virtudes morais. Destacando ainda que a instrução não era apenas um adorno, mas necessária para todos aqueles que fossem seguir a profissão de armas, para os civis, os políticos, para todos se beneficiarem do conhecimento científico (CARDOZO, 1996).

É possível verificar que até o momento a preocupação com a formação intelectual voltava-se, possivelmente, apenas aos homens, pois mesmo diante de outras literaturas, as orientações propostas ao trato com as crianças voltavam-se aos "maestros", orientando-os a agir como bons pais de família, como no excerto que segue:

La mejor enseñansa que el maestro podia imparitir era com su própia conducta. Los niños jamás aprenderán la educación moral si no la vem practicar. [...] Em consequência, al maestro debía adornale las cualidades próprias de um buen padre de família. Su primer empeño tenía que consistir em estudiar e profundizar el gênio, inclinación, talento y pasiones de los niños para dirigirlos con prudência y sujetarlos a los limites da la razón, reconiciendo la desigual condición de los mismos (CARDOZO, 1996, p. 232233).

A preocupação com a formação das mulheres só ganhou espaço na história da educação paraguaia por volta de 1890, quando começou a ser estruturada a Escuela Graduada de Preceptores, a qual serviu de base para a Escuela Normal de Maestras de Assunção. As irmãs Adela e Celsa Speratti, após terem realizado um excelente trabalho 
na famosa Escuela Normal de Concepción, no Uruguai, foram convidadas pelo presidente Juan G. González para colaborarem com a criação da escola paraguaia e em 1896 a Escuela Normal de Maestras foi fundada oficialmente, em função dos esforços de Manuel Amarilha e sob a direção de Adela Speratti até o ano de 1902, quando a mesma faleceu. Assumindo a direção sua irmã Celsa Speratti, até 1905. Hoje a Escuela Normal de Maestras é denominada de Escuela Normal de Professores No 1.

As Escolas Normais foram se multiplicando em todo o país, especialmente no interior e, para atender a esta demanda, foi necessário que o número de professores também aumentasse significativamente. Estudos como os de Cardozo (1996) e Seiferheld (2016) destacam que durante a era liberal, com as tensões e acontecimentos desencadeados pela Guerra do Chaco (1932-1935), muitas adaptações aconteceram na sociedade e na comunidade escolar, a qual tentou não paralisar suas atividades, mas sofreu com os impactos da guerra, pois em vários momentos teve que produzir insumos para atender aos soldados e transformar suas salas de aula em hospitais, poupando apenas a educação primária.

Como um dos resultados da guerra Seiferheld (2016) destaca uma maior representatividade feminina na sociedade paraguaia e a consequente ampliação das possibilidades formativas para a mulher, principalmente porque diante da morte de muitos homens durante o combate, as mesmas assumiram funções fora de seus lares, substituindo os homens em setores públicos e comerciais.

Outro aspecto resultante da guerra é que com seu término várias escolas foram reativadas e assim o acesso das crianças à escola e à educação primária evidenciou bons efeitos, o que gerou a elaboração de um novo Plano de estudos, apoiado pela Organização das Nações Unidas para a Educação, a Ciência e a Cultura (UNESCO).

Entretanto, as tensões e instabilidades causadas pelos ideais fascistas de governos autoritários culminaram com o surgimento da ditadura de Stroessner em 1954, perdurando até 1989. Esta apresentava um forte caráter opressor, perseguindo, prendendo e exilando muitas pessoas e instituições que desenvolviam atividades no campo do pensamento social, da educação e da produção de conhecimento. Porém o discurso propagado pelo governo buscava manter a ideia de paz, em ações que se diziam em prol do bem social e do progresso da nação, camuflando as ações violentas e autoritárias do governo. 
A intenção era manter a população em seu poder, como fizera com os/as professores/as, os/as quais deviam se filiar ao partido do governo como forma de manter sua lealdade ao mesmo, entretanto concediam-lhe o elemento de controle, poder e vigilância de suas ações. Cabe destacar que aqueles profissionais que não aceitavam se filiar ao partido tinham suas atividades políticas e sociais monitoradas por supervisores escolares, que geralmente eram membros ativos do governo, entretanto essa vigilância seguia uma perspectiva diferente (SEIFERHELD; D“eALESSANDRO, 2018).

Neste sentido, é possível considerar que esta sociedade de indivíduos mais organizados e interdependentes entre si, com historicidades que ora se aproximam e ora se distanciam, principalmente no que se refere à contextualização histórica dos processos de formação docente para a infância, passa a ser muito mais evidente e significativa quando, por meio da História Oral, estes indivíduos contam suas vivências, são levados a buscar em suas memórias acontecimentos, fatos, situações que tenham feito parte de sua vida e que de alguma forma, por meio da psicogênese do indivíduo, possam entrelaçar-se com o meio social, de acordo com os princípios da sociogênese, e evidenciar a configuração de várias redes de interdependências que evidenciam o processo histórico pelo qual estes indivíduos passaram a repensar em sua profissão, em sua vida e em muitos outros aspectos que foram desencadeados através da metodologia do trabalho com a História Oral. Pois como destacam Sarat e Santos:

Trabalhar com a história oral torna-se possibilidade de ouvir não somente minorias, mas valorizar todos aqueles que estejam representados nas pesquisas e investigações, valorizando vozes de pessoas, trajetórias de vida, memórias, biografias, histórias que possam dar respostas aos nossos questionamentos (2010, p. 51).

Buscamos compreender como todo este processo de "constituir-se professora", da "escolha da profissão" e algumas "vivências mais significativas com as crianças" realmente aconteceu com uma professora, hoje aposentada, mas que lecionou por mais de trinta anos em escolas de Pedro Juan Caballero (PY), e que ao se deparar com a possibilidade de contar as suas memórias, sentiu-se emocionada e motivada a buscar aquilo que vivenciou e trazer para o presente, a fim de colaborar com a constituição histórica de suas vivências enquanto professora da infância. 


\title{
A ENTREVISTA E A ENTREVISTADA: EDUCAÇÃO, MEMÓRIA E IDENTIDADE DOCENTE
}

A metodologia da História Oral, que pode ser entendida como um procedimento que usa a entrevista como instrumento para fazer registros das narrativas de experiências de indivíduos se configura como uma riquíssima ferramenta que auxilia na compreensão do processo de desenvolvimento da sociedade a partir de histórias de pessoas que nela vivem.

\begin{abstract}
A História Oral, pois é, mais que um arquivo de gravações. Implica a elaboração de um documento que pode ser, num primeiro momento a transcrição do testemunho e, em outra etapa, a sua análise. O primeiro estágio implica objetividade, o segundo admite graduações dependendo mais de quem interpreta (MEIHY, 1994, p. 53).
\end{abstract}

A metodologia abre caminhos para a revelação de histórias para quem conta e para quem ouve, permite um ir e vir no tempo, ao longo de vivências e emoções, que se configuram em representações para pesquisador e na rememoração de aspectos selecionados pelo pesquisado, segundo Delgado:

\begin{abstract}
Ao se dedicar à análise do passado, o estudioso da História vai ao encontro de um outro tempo diferente daquele no qual está integrado. Nessa viagem realiza-se um amálgama peculiar caracterizado pelo encontro de singularidades temporais. Trata-se do encontro da História já vivida com a história pesquisada, estudada, analisada, enfim, narrada (DELGADO, 2003, p. 10-11).
\end{abstract}

Esta narração constitui a historicidade do pesquisado, permite ao pesquisador a construção da interpretação do vivido não modificando a essência do narrado, tal como destaca Meihy (1994) e de acordo com o que propõe Delgado, visto que:

[...] ao se interpretar a história vivida, no processo de construção da história do conhecimento, os historiadores são influenciados pelas representações e demandas do tempo em que vivem e a partir dessas representações e demandas, voltam seus olhos para o vivido reinterpretando-o, sem no entanto, o modificar (2003, p.10). 
No processo de desenvolvimento desta metodologia, a construção de olhares diferenciados acerca do narrado, a interpretação e reinterpretação das ações e situações revisitadas, as emoções e sentimentos que voltam a permear o presente são inevitáveis por parte de quem narra, e em muitos momentos, geram tensão, sentimentos conflitantes e inquietantes em quem ouve, pois, desencadeiam a necessidade de querer ouvir mais, de conhecer e analisar mais a fundo os acontecimentos que marcaram a história investigada, em função da temporalidade e da construção relacional entre o presente e o passado, pois.

\footnotetext{
O tempo é um movimento de múltiplas faces, características e ritmos, que inserido à vida humana, implica em durações, rupturas, convenções, representações coletivas, simultaneidades, continuidades, descontinuidades e sensações (a demora, a lentidão a rapidez). É um processo em eterno curso e em permanente devir. Orienta perspectivas e visões sobre o passado, avaliações sobre o presente e projeções sobre o futuro (DELGADO, 2003, p. $10)$.
}

A entrevista com uma professora de Pedro Juan Caballero (PY), a qual foi escolhida por ter trabalhado com a infância desde a década de 1970 na região de fronteira, consistiu em ouvir sua narrativa com o propósito de compreender como o "constituir-se professora", "a escolha da profissão" e algumas de suas "vivências mais significativas com as crianças" podiam ser revisitadas e trazidas para o tempo presente a partir da sua memória.

A emoção sobre o vivido e as representações de tudo que foi rememorado corroborou para reforçar o caráter social da História Oral como metodologia que avança no campo científico, principalmente no que tange ao referendar que o trabalho com a História Oral “[...] enquanto método e prática no campo de conhecimento histórico, reconhece que a trajetória dos indivíduos e dos grupos merecem ser ouvidas, também as especificidades de cada sociedade devem ser conhecidas e respeitadas" (MATOS; SENNA, 2011, p.107).

Características estas relevantes para o contexto da fronteira entre Brasil e Paraguai, o qual apresenta formas peculiares de configurações sociais, culturais e educacionais, o que faz com que os/as profissionais que desenvolvem suas atividades nesse meio ajam de formas particulares, ressaltando assim a importância de conhecê-las, analisá-las e socializá-las, buscando ampliar seus direitos em meio às transformações 
pelas quais passa e pode ocasionar na própria realidade da qual faz parte, o que, segundo Meihy (2006) é visto como um dos objetivos-fim da História Oral, a possibilidade de transformação:

\begin{abstract}
Se, contudo, diversamente buscarmos o sentido social do conhecimento, chegaremos a uma postura, política e até militante, que vê a história oral como um recurso de transformação e não apenas como acesso ao conhecimento a informação. É evidente que a busca do conhecimento e informação como meio de transformação é o objetivo do que estou convencionando chamar de história oral, mas, como fim, não como meio (MEIHY, 2006, p.194).
\end{abstract}

O que levou a realização da entrevista com uma professora que desenvolveu suas práticas docentes com a infância na cidade de Pedro Juan Caballero (PY) justificase pelo fato de que este trabalho está associado a uma pesquisa mais ampla, a qual objetiva estudar as trajetórias docentes de professoras da infância, no contexto da fronteira. Assim, conhecer as vivências da professora que, por ora será apresentada, permite-nos compreender um pouco melhor alguns aspectos históricos da sua formação, de sua trajetória docente, e da constituição da história da educação na fronteira.

O recorte temporal foi delimitado entre o período de 1970 e 1980, pois como a própria entrevistada destaca, foi o início de suas práticas profissionais com a infância. Momentos estes que serão de fundamental importância para a compreensão sobre as memórias da professora.

A entrevistada, professora Renata $^{4}$, destacou a satisfação em poder participar de alguns momentos de conversas e interações, aceitou prontamente e mostrou-se interessada em contribuir. Em um de nossos primeiros contatos disse que gostava muito de se lembrar do que havia feito enquanto trabalhava como professora.

Essa possibilidade tão rica de revisitar as memórias e tudo que foi feito em um tempo passado e que, às vezes de forma meio tímida volta a aflorar no pensamento de quem narra, passa a ser um importante artifício para a configuração de situações, momentos, experiências que já se encerraram, mas continuam vivas dentro de si, como marcas preciosas, e que a memória consegue externar nessa constituição da identidade, da essência do ser que está a falar sobre o vivido. Assim como define Bobbio:

\footnotetext{
${ }^{4} \mathrm{O}$ nome Renata é usado de forma fictícia, seguindo todo o rigor exigido para o desenvolvimento da pesquisa científica.
} 
O relembrar é uma atividade mental que não exercitamos com frequência por que é desgastante ou embaraçosa. Mas é uma atividade salutar. $\mathrm{Na}$ rememoração reencontramos a nós mesmos e a nossa identidade, não obstante muitos anos transcorridos, os mil fatos vividos. [...] Se o futuro se abre para a imaginação, mas não nos pertence mais, o mundo passado é aquele no qual, recorrendo a nossas lembranças, podemos buscar refúgio dentro de nós mesmos, debruçarmos sobre nós mesmos e nele reconstruir nossa identidade (1997, p. 30-31).

A professora Renata demonstrou esta caminhada introspectiva por suas memórias e, consequentemente a reconstrução de sua identidade de forma magistral, pois trouxe para o tempo presente não só os fatos acontecidos, mas a emoção em sua fala, o sentimento em suas ações e o brilho no olhar ao contar suas experiências que o tempo permanecido ao seu lado transcorreu de forma que não percebemos, e nossos diálogos reforçaram a importância de se pesquisar a trajetória de vida desta professora.

Renata tem 76 anos, nascida em Pedro Juan Caballero, conta que começou a estudar em sua cidade natal, por volta de 1958, fazia o curso Normal, para se tornar "Maestra", professora para trabalhar com crianças. Entretanto, ela fala que parecia que não era esta a profissão que queria seguir, mas que com o tempo foi se acostumando com a ideia e depois passou a gostar: "Eu comecei a me formar aqui na escola Normal, comecei a estudar aqui, mas parecia que não era a minha profissão, aquilo que eu queria, que eu gostava, mas com o tempo fui estudando, estudando, fui me adaptando e fui gostando" (RENATA).

Diante do fato destacado pela professora Renata, principalmente no trecho em que fala que "parecia que não era a minha profissão", questionei o que a levou buscar esta formação e ir para uma sala de aula, e a resposta foi:

\footnotetext{
Porque não havia outra faculdade, nada! Era somente contabilidade, depois era o $6^{\circ}$ curso, não, havia uma escola assim como bacharelado, mas você tinha que estudar, comércio, por exemplo, tinha que fazer desde o $1^{\circ}$ curso, até o $6^{\circ}$, aí você se formava comerciante, depois se fosse fazer bacharelado, para poder entrar na faculdade. E o magistério era terminar o $6^{\circ}$ curso e você já tinha o seu trabalho, era mais fácil, antigamente. Isso cada vez levava uma a fazer; isso me levou a fazer, porque eu não teria condições de ir, por exemplo, morar em Assunção para poder estudar. Justo neste ano que eu ia começar a estudar se fechou o "Professoral", para ser professora superior [...] E este ano que eu ia começar a estudar se fechou (com muito pesar!!), foi o último ano e eu sou apenas professora primária (RENATA, grifo nosso).
} 
Pelo contexto apresentado na fala da professora Renata, pode-se perceber que, por mais que o "ser professora" não fosse de início a sua primeira opção, as muitas circunstâncias da vida e da sua historicidade a levaram para este caminho. Fato que segundo Louro (1997), mediante às transformações pelas quais passavam a sociedade brasileira na década de 1970, a busca pelo magistério era uma forma de a mulher conseguir sua colocação no mercado de trabalho.

Assim, vemos que o mesmo acontecia no cenário paraguaio, pois Renata ressalta que em função de o curso Normal poder colocá-la de uma forma mais rápida em contato com o mercado de trabalho, e o curso de contabilidade ser noturno e predominantemente masculino, a opção que tinha era a escolha por ser professora primária, visto que a oferta de um curso que formava professoras para o nível superior na região deixou de ser ofertado.

Esta narrativa nos faz compreender muitos acontecimentos e escolhas do mesmo, e assim a professora Renata continua sua rememoração, com o propósito de também compreender a escolha por sua profissão. Ela conta ainda que em Pedro Juan Caballero havia poucas alunas que queriam seguir a carreira do magistério e que como teve que ir para Assunção, a capital do País, para acompanhar seu pai em um tratamento médico, aproveitou também para terminar seu curso Normal. Em 1963 ela já estava formada e diz que quando voltou para Pedro Juan Caballero, em 1964, chegou e já começou a trabalhar:

Eu vim em 64, já formada, e foi aí que eu comecei, quando cheguei aqui já tinha um lugar para trabalhar. Comecei trabalhando com o $2^{\circ}$ grau, com gente maior, sete, oito, nove anos [...] foi um pouco difícil porque foi a primeira vez, eu não tinha praticamente nenhum contato com os pequenos, a não ser nas práticas que tínhamos. Tínhamos muitas práticas, mas não era igual estar em aula, não era igual (RENATA).

A professora ressalta que como processo de formação fez dois anos de um curso preparatório e depois mais quatro anos de formação no Normal, o que lhe assegurou finalizar o " 6 curso" e poder começar a trabalhar no ensino primário. Ela observava que para trabalhar com os pequenos fez ainda outro curso que se chamava "Parvularia, específico para trabalhar com los niños" (RENATA). Reforçando que à época não era como agora, que tem que se fazer um curso superior, no qual se fundamenta muito mais 
teorias e práticas. Ela fala que naquela época, muitas coisas eram aprendidas na prática mesmo, no dia a dia com as crianças.

Este contexto nos leva a vislumbrar que suas vivências eram ressignificadas mediantes as necessidades com as quais se deparava, pois ela menciona que havia mudanças propostas pelo governo, às quais as professoras precisavam se adaptar, mas que isso não tornava o trabalho menos gratificante, visto que mesmo em meio a muitas dificuldades, tal como salas repletas de crianças e a inexistência de auxiliares para lidar dia a dia com mais de 30 alunos, ela se sentia muito grata por poder contribuir com a formação intelectual e pessoal daquelas crianças. Ao ser questionada sobre que tipo de história construiu com aquelas crianças e qual a contribuição dela enquanto professora, Renata destaca que:

Eu era praticamente a segunda mãe delas, e isso me motivou, porque agora, por exemplo, há alunos que me reconhecem e dizem "professora!!" [...] (fala emocionada) e se sentem agradecidos, e eu também, porque recordo deles como se fossem meus filhos, estou feliz por ter contribuído para que essas crianças chegassem ao que são hoje, profissionais, assim (RENATA, grifo nosso).

Renata nos mostra que ao rememorar suas práticas enquanto professora de crianças, traz, mesmo que de forma tímida, uma importante análise do seu papel diante da contribuição no processo formativo destes pequenos. Assim como ao relatar, de forma emocionada sobre um ex-aluno chamado Gustavo: “[...] hoje em dia é reconhecido, mora em Assunção, cada vez que ele vem aqui, que tem a mãe dele aqui, ele vem e me vê" (RENATA).

Buscando em suas memórias as lembranças da profissão, Renata compartilha com quem a ouve e, consequentemente com quem lê estes escritos, momentos de construção e rememoração de sua historicidade, pois o ir e vir de seus relatos faz aflorar sentimentos que estavam apaziguados, emerge o pensar acerca de uma identidade muito peculiar e ressignifica práticas que por anos permaneceram ocultas em sua memória. Assim, dialogamos com Sarat, quando ela destaca que:

Quando a pessoa está contando fatos de sua vida ela acredita que aquilo aconteceu, vai valorizando ou desvalorizando determinadas situações, lembrando dos acontecimentos mais significativos e selecionando, por meio da memória, fatos a serem contados. A narrativa feita no momento presente 
torna-se, carregada das imagens e representações que ela faz do acontecimento passado (SARAT, 2004, p.61).

Ao narrar suas memórias a professora Renata não as fez de forma linear, mas as retomou de acordo com as situações lembradas, a relevância dos acontecimentos e a vivacidade que o contato com a História Oral lhe possibilitou, evidenciando assim a constituição histórica da sua formação docente e também das relações pessoais que a configuraram como este indivíduo constantemente imbricado e interdependente às relações sócio-históricas que Elias (1994) propõe.

\section{CONSIDERAÇÕES FINAIS}

Refletir e escrever sobre as vivências de uma professora da infância, a qual buscou em suas memórias seu processo de formação e alguns momentos mais significativos de sua prática docente, trazendo para o tempo presente aspectos relevantes de uma história que foi vivida e que agora, ao ser relembrada, torna-se repleta de novos significados e emoções, permite a estruturação da história de vida desta professora que trabalhou na fronteira entre Brasil e Paraguai, e porque não dizer, da constituição da História da Educação Fronteiriça.

Utilizar a metodologia da História Oral possibilitou que este trabalho valorizasse as experiências da Professora Renata, que em todos os momentos das entrevistas se mostrou muito satisfeita em poder colaborar e compartilhar conosco um pouco de sua história, visto que ao propor esta forma de trabalho dialogamos com Portelli, quando este destaca que “[...] cada pessoa é um amálgama de grande número de histórias em potencial [...]. Cada entrevista é importante, por ser diferente de todas as outras" (1997, p. 17).

E assim aconteceu com a professora Renata, suas entrevistas foram extremamente importantes para que o caráter do trabalho com a História Oral fosse melhor compreendido, mas principalmente, possibilitou que lançássemos um olhar mais profícuo acerca da trajetória desta docente da infância em seu contexto de trabalho na fronteira, instigando-nos, portanto, a continuar esta investigação, por meio da História Oral, buscando conhecer novas histórias destas mulheres professoras que arduamente 
construíram seu caminho no trabalho com a infância e na constituição da história da educação fronteiriça.

\section{REFERÊNCIAS BIBLIOGRÁFICAS}

BALLER, Leandro. Fronteira e Fronteiriços: a construção das relações socioculturais entre brasileiros e paraguaios (1945-2014). Curitiba, PR: CRV, 2014.

BOBBIO, Noberto. O Tempo da memória. Rio de Janeiro: Campus, 1997.

BRASIL. IBGE. Censo Demográfico, 2020. Disponível em: <https://cidades.ibge.gov.br/brasil/ms/ponta-pora/panorama>. Acesso em: 16 de out. de 2020.

BRASIL. Portaria n. 125, de 21 de março de 2014. Estabelece o conceito de cidadesgêmeas nacionais, os critérios adotados para essa definição e lista todas as cidades brasileiras por estado que se enquadram nesta condição. Disponível em: $<$ http://pesquisa.in.gov.br/imprensa/servlet/INPDFViewer?jornal=1\&pagina $=45 \&$ data $=$ 24/03/2014\&captchafield=firistAccess $>$. Acesso em: 16 de out. de 2020.

CARDOZO, Efraim. Apuntes de la Historia Cultural del Paraguay. Paraguay: Editorial El Lector, 1996.

DELGADO, L.A.N. História oral e narrativa: tempo, memória e identidades. Dossiê b/, História Oral, 6, 2003, p. 9-25.

DGEEC - Dirección General de Estadísticas, Encuestas y Censos. Assunção, Paraguay, 2015. Paraguay. Proyección de La Población por Sexo y Edad, Según Distrito, 2000-2025. Revisión 2015. Disponível em: https://www.dgeec.gov.py/microdatos/indicador.php?ind=MTY=. Acesso em: $17 \mathrm{de}$ out. de 2020.

DURAN, M. C. G. Profissão docente: desafios de uma identidade em crise. Formação Docente: Revista Brasileira de Pesquisa sobre Formação de Professores. v. 02, n. 02, p. 46-53, jan.-jul. 2010. Disponível em: <http://formacaodocente.autenticaeditora.com.br>. Acesso em: 10 de maio de 2013.

ELIAS, Norbert. O Processo Civilizador. Volume 1: Uma história dos costumes. Rio de Janeiro: Jorge Zahar, 1994.

MATOS, V. J; SENNA, K. A. História Oral como Fonte: problemas e métodos. Revista História. Rio Grande, 2 (1): 95-108, 2011.

MEIHY, José Carlos Bom. Definindo História Oral e Memória. Cadernos $C E R U-\mathrm{n}^{\circ}$ 5- Série 2: 1994. 
MEIHY, José Carlos Bom. Os Novos Rumos da História Oral: o caso brasileiro. Revista de História 155 v 2º: 2006. p.191-203.

PORTELLI, A. Tentando aprender um pouquinho: algumas reflexões sobre ética na história oral. Projeto História, São Paulo, n. 15, p. 13-49, abr. 1997.

SARAT, Magda. Formação profissional e Educação Infantil: Uma história de contrastes. Revista Guairacá, 17:135-158, 2001.

SARAT, Magda. História da Formação de Professoras para a Infância: Experiências no Brasil e na Argentina. Revista Teoria e Prática da Educação, v. 18, n.1, p. 23-36, Janeiro/Abril 2015.

SARAT, Magda. Histórias de Estrangeiros no Brasil: infância, memória e educação. 2004. Tese de Doutorado. Arquivo Pessoal.

SARAT, Magda; SANTOS, Reinaldo dos. História Oral como fonte: apontamentos metodológicos e técnicas da pesquisa. In: COSTA, C. J. ; MELO, J. J. P. e FABIANO, L. H. (org.) Fontes e Métodos em História da Educação. Dourados: Ed. UFGD, 2010. p. 49-78.

SEIFERHELD, David Velásquez. Relaciones entre autoritarismo y Educación em el Paraguay: 1869-2012. Un análisis histórico. Primer Volumen 1869-1936. SERPAJ: Paraguay, 2016.

SEIFERHELD, David Velásquez; D ALESSANDRO, Sandra. Relaciones entre autoritarismo y Educación em el Paraguay: 1869-2012. Un análisis histórico. Tercer Volumen 1954-1989. SERPAJ: Paraguay, 2018.

SILVA, Luciene Cléa da. Trajetórias de Formação de Professoras da Infância na Fronteira de Ponta Porã/BR e Pedro Juan Caballero/PY. 2020. Tese (Doutorado em Educação) - Universidade Federal da Grande Dourados, 2020. Disponível no Repositório Institucional da UFGD em: <https://portal.ufgd.edu.br/setor/biblioteca/repositorio>.

TANURI, Leonor Maria. História da formação de professores. Revista Brasileira de Educação. Mai/Jun/Jul/Ago: 2000. 